
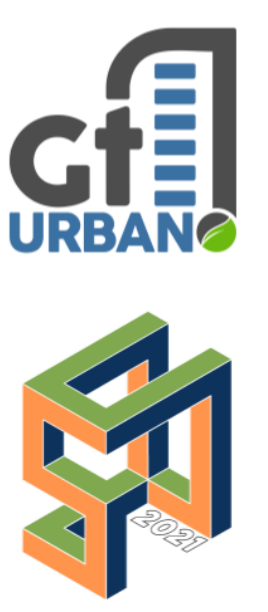

\section{SINGEURB}



Como citar:

CHARLES, Mariana

R.; RODRIGUES,

Rafael F. T.;

OLIVEIRA, Renata de

O.; BARROS,

Romildo J. B. R.;

JUNIOR, Mauro H.

A. L. A

universalização do

serviço de

saneamento básico e a

governança no Estado

do Rio de Janeiro. In:

III SIMPÓSIO

NACIONAL DE

GESTÃO E

ENGENHARIA

URBANA:

SINGEURB, 2021,

Maceió. Anais... Porto

Alegre: ANTAC,

2021. p. 45-54.

Disponível em:

https://eventos.antac.

org.br/index.php/sing

eurb/issue/view/14

\title{
A universalização do serviço de saneamento básico e a governança no Estado do Rio de Janeiro
}

\author{
The universalization of basic sanitation and the \\ governance in the state of Rio de Janeiro
}

Mariana Ribeiro Charles, Universidade Federal do Rio de Janeiro (UFRJ), marianacharles@poli.ufrj.br

Rafael Felipe Teixeira Rodrigues, Universidade Federal do Rio de Janeiro (UFRJ), rafaelftr@poli.ufrj.br

Renata de Oliveira e Oliveira, Universidade Federal do Rio de Janeiro (UFRJ), renataduzzo@poli.ufrj.br

Romildo José Barbosa do Rêgo Barros, Universidade Federal do Rio de Janeiro (UFRJ), romildorbarros@poli.ufrj.br

Mauro Henrique Alves de Lima Junior, Universidade Federal do Rio de Janeiro (UFRJ), mhaljr@poli.ufrj.br

\section{RESUMO}

A universalização dos serviços de saneamento é a principal meta das empresas do setor, desde a promulgação da Lei Federal № 14.026, em 15 de julho de 2020, que atualiza o Marco Legal do Saneamento Básico. A concretização do leilão de Privatização da Companhia Estadual de Águas e Esgotos do Rio de Janeiro (CEDAE) tem motivado discussões na sociedade que perpassam por política, economia, saúde pública e meio ambiente e, neste sentido, este trabalho vem lançar luz sobre a discussão. Este artigo apresenta dados históricos que retratam a importância da estatal para o saneamento a nível nacional e local, e compara dados de desempenho em quesitos de governança nesta e em outras empresas da iniciativa privada que atuam no ramo. Tais dados mostram que contratos de concessão, bem redigidos, com objetivos bem delimitados e especificação de direitos e obrigações das partes envolvidas, podem ser extremamente benéficos à sociedade e podem contribuir para que o objetivo final do Marco Legal seja alcançado: a universalização dos serviços de saneamento até 2033. A importância do tema analisado neste artigo vai além do notório impacto positivo do saneamento na vida da população, mas provoca uma reflexão acerca da desestatização destes serviços sob a ótica da governança e eficiência técnica.

Palavras-chave: Universalização, Governança, CEDAE.

\begin{abstract}
The universalization of sanitation services has been the main goal of companies in the sector, since the law $n^{0}$ 14.026, which updates the Legal Framework for Basic Sanitation. The achievement of the privatization auction of the State Water and Sewage Company of Rio de Janeiro (CEDAE) has motivated discussions in society that go through politics,
\end{abstract}


economy, public health and the environment, and in this context, this work sheds light on that discussion. This article presents historical data that shows the importance of that stateowned company for sanitation in the national and local level, and compares performance data on governance issues in this company and other private companies which operate in the sanitation market. Such data show that well-written concession contracts, with well-defined objectives and specification of the rights and obligations of the parties involved, may be extremely beneficial to society and can contribute to achieving the final objective of the Legal Framework: the universalization of sanitation services until 2033. The value of this theme analyzed in this article goes beyond the notorious positive impact of sanitation on the population's life, but it brings a reflection about the privatization of these services from the perspective of governance and technical efficiency.

Keywords: Universalization, Governance, CEDAE.

\section{INTRODUÇÃO}

O acesso ao serviço de saneamento básico no Brasil é direito determinado pela Lei da Política Nacional de Saneamento Básico (BRASIL, 2007), cujos princípios fundamentais são a universalização e a integralidade dos serviços de abastecimento de água, esgotamento sanitário, manejo de resíduos sólidos, proteção e gestão dos recursos hídricos, integração com políticas de uso do solo e promoção da equidade social. $\mathrm{O}$ Plano Nacional de Saneamento Básico (PlanSab) apresenta diretrizes para que cada entidade federativa elabore políticas públicas conforme sua abrangência (MDR, 2019). O Quadro 1 apresenta cenários possíveis de participação pública e privada para a gestão do saneamento básico mirando a universalização.

\begin{tabular}{|c|c|c|c|}
\hline Condicionante & Universalização & Busca da Universalização & $\begin{array}{c}\text { Distante da } \\
\text { Universalização }\end{array}$ \\
\hline $\begin{array}{c}\text { Papel do Estado(modelo } \\
\text { de desenvolvimento)/ } \\
\text { Marco } \\
\text { regulatório/Relação } \\
\text { interfederativa }\end{array}$ & $\begin{array}{c}\text { Estado provedor e } \\
\text { condutor dos serviços } \\
\text { públicos com } \\
\text { participação do setor } \\
\text { privado e forte } \\
\text { cooperação entre os entes } \\
\text { federativos }\end{array}$ & $\begin{array}{l}\text { Redução do papel do } \\
\text { Estado, participação do } \\
\text { setor privado em funções } \\
\text { públicas essenciais e } \\
\text { moderada cooperação } \\
\text { entre os entes }\end{array}$ & $\begin{array}{c}\text { Estado mínimo com } \\
\text { mudanças nas regras } \\
\text { regulatórias e conflitos } \\
\text { na relação } \\
\text { interfederativa }\end{array}$ \\
\hline $\begin{array}{l}\text { Gestão, gerenciamento, } \\
\text { estabilidade e } \\
\text { continuidade de políticas } \\
\text { públicas / participação e } \\
\text { controle social }\end{array}$ & $\begin{array}{c}\text { Avanços na capacidade } \\
\text { de gestão com } \\
\text { continuidade entre } \\
\text { mandatos }\end{array}$ & $\begin{array}{l}\text { Políticas de Estado } \\
\text { contínuas e estáveis }\end{array}$ & $\begin{array}{c}\text { Prevalência de políticas } \\
\text { de governo }\end{array}$ \\
\hline Investimento no setor & $\begin{array}{l}\text { Crescimento do patamar } \\
\text { dos investimentos } \\
\text { públicos e privados } \\
\text { submetidos ao controle } \\
\text { social }\end{array}$ & $\begin{array}{c}\text { Aumento dos } \\
\text { investimentos públicos e } \\
\text { privados, parcialmente } \\
\text { com critérios de } \\
\text { planejamento, insuficientes } \\
\text { para a universalização }\end{array}$ & $\begin{array}{l}\text { Diminuição do atual } \\
\text { patamar de } \\
\text { investimentos públicos } \\
\text { e privados aplicados } \\
\text { sem critérios }\end{array}$ \\
\hline
\end{tabular}

Fonte: Adaptado de Brasil (2019) 
No Rio de Janeiro foi promulgada a Lei Estadual no 7.529/2017 que autoriza o poder executivo a alienar ações representativas do capital social da Companhia Estadual de Águas e Esgotos (CEDAE), em ambiente de insuficiente debate público sobre a matéria e com incongruências quanto ao atendimento de normas constitucionais relativas aos planos financeiros e orçamentários (GONÇALVES, 2017).

\section{A HISTÓRIA DO SANEAMENTO NO ESTADO DO RIO DE JANEIRO E O ESTABELECIMENTO DA CEDAE}

Os registros do início da ocupação do território fluminense mostram que não havia organização sistemática de destinação de dejetos como de captação de água para consumo. As famílias que dispunham de mão de obra escrava lançavam suas excretas em mananciais mais afastados, não havendo esse controle por parte de toda a população, o que acarretava poluição dos corpos hídricos às margens das ocupações (GONÇALVES, 2017). A Figura 1 ilustra a história do saneamento no estado do Rio de Janeiro.

Figura 1 - Histórico do saneamento no Estado do Rio de Janeiro

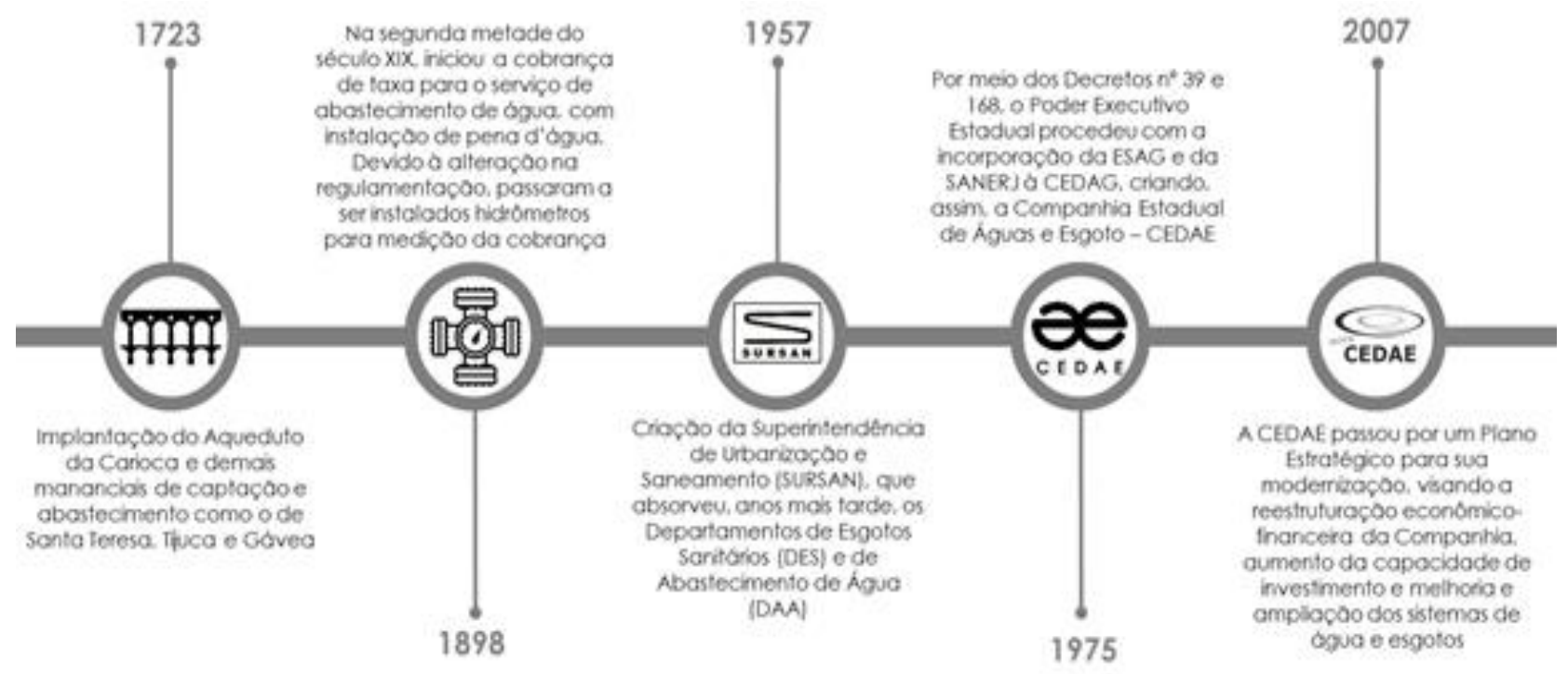

Fonte: Adaptado de Gonçalves (2017) e Nascimento (2010)

Para Gonçalves (2017), a concepção da CEDAE sob a forma de sociedade de economia mista ia de encontro à abordagem empresarial que rondava os serviços de água e esgoto na época, partindo da premissa de que haveria autossustentação tarifária nos serviços, isto é, a viabilização de investimentos para expansão das redes a partir de excedentes obtidos em áreas superavitárias.

Os efeitos da extinção do Banco Nacional da Habitação (BNH), em 1986, e da grave crise econômica vivida no Brasil na década de 1980 acabaram contribuindo para o endividamento das Companhias Estaduais de Saneamento Básico (CESBs). Em 2007 a CEDAE passou por reestruturação e deu origem à "Nova CEDAE", impactando positivamente na Companhia, de forma que, em 2017, esta chegou a ser avaliada em 7 bilhões de reais (GONÇALVES, 2017).

De acordo com CEDAE (2016), o Planejamento Estratégico da empresa (PE 2017-2021, ano do leilão) vislumbrava, entre outros objetivos: melhorar sistemas e processos internos além de melhorar e ampliar a prestação de serviços de água e esgoto, definindo formas de parcerias. Mesmo após a transformação da estatal na "Nova CEDAE", a própria empresa admite grandes desafios na área de governança corporativa 
para atingir seus objetivos de curto e médio prazos. Ao analisar o PE 2017-2021 é possível identificar ausência de mecanismos de avaliação, monitoramento e controle, o que pode impactar negativamente no desempenho da companhia.

\section{GOVERNANÇA E O PROCESSO DE CONCESSÃO DOS SERVIÇOS DA CEDAE}

O processo de privatização da CEDAE acontece em meio a um cenário de crise global de saúde, onde a presença da água é fator determinante para a proteção contra possíveis infecções. Soma-se a isso, eventos de contaminação da água na lagoa próxima à captação no Rio Guandu, resultando em sabor e odor desagradáveis à água tratada na ETA (estação de tratamento de água) Guandu, fato que se arrastou por meses (CEDAE, 2021b). Sem saber se estava sujeita a contaminação ou doenças, a população se viu obrigada a recorrer à compra de carros-pipa e água mineral.

Poucos meses antes, a promulgação da Lei 14.026/20, mais conhecida como o Novo Marco Regulatório do Saneamento Básico, reforça um movimento já aquecido de desestatização na área de infraestrutura, onde estimula a concorrência no setor, fomentando a entrada de novas empresas e investidores privados por meio de inovações necessárias à nova realidade (ANTUNES e D'OLIVEIRA, 2020). Segundo Vassalo e Stefano (2021), um estudo publicado pela Fundação Getúlio Vargas (FGV) aponta que somente 2\% dos contratos de prestação de serviço entre a estatal e os municípios onde atua têm metas definidas, o que ataca frontalmente a eficiência e o desempenho de qualquer empresa. Para solucionar esse ponto crítico, o Novo Marco traz, como uma de suas inovações, a técnica de regulação por performance, baseada em metas de desempenho, ou seja, redução de perdas, melhoria da qualidade e a universalização de serviços passam a ser, entre outras, condições sine qua non do contrato de concessão.

O leilão ocorrido no dia 30 de abril de 2021 arrecadou $R \$ 22$ bilhões para os cofres públicos, que serão liberados em parcelas ao longo dos próximos anos (TRIGUEIRO, 2021). A motivação para a privatização de parte das operações da empresa passa pelo plano de vendas de ativos e concessões baseadas em Parcerias Público Privado (PPP) e é endossada pela evidente precariedade de governança da estatal. Além disso, a CEDAE já havia sido dada como garantia por parte do Governo do Estado do Rio de Janeiro para adesão ao Regime de Recuperação Fiscal (RRF) em 2017. Com a concretização do leilão, abre-se um horizonte para a universalização dos serviços até 2033, ampliação da tarifa social e investimentos obrigatórios em infraestrutura de favelas e projetos de despoluição (SILVEIRA, 2021).

\section{DESEMPENHO DE OPERADORES PRIVADOS VERSUS OPERADORES ESTATAIS}

Para efeitos de comparação, dados do Sistema Nacional de Informações Sobre Saneamento - SNIS mostram que o país evoluiu muito pouco na extensão da rede coletora de esgoto, havendo um aumento de cerca de $17 \%$ na cobertura do serviço, passando de $46,2 \%$ da população brasileira (segundo o IBGE, mais de 212 milhões de habitantes) com acesso este serviço para 54,1\% em 9 anos (2010-2019). Em relação ao abastecimento de água, cuja cobertura já se mostrava percentualmente maior em 2010 (81,1\%), houve uma expansão menor ainda da rede, registrando crescimento da ordem de $3 \%$ no mesmo período, totalizando 83,7\% da população atendida com rede de abastecimento de água em 2019 (SNIS, 2021a).

Ainda em relação aos efluentes gerados, dados do mesmo painel evidenciam a precariedade do país no quesito tratamento de esgoto. O Gráfico 1 compara as evoluções do Estado do Rio de Janeiro e do País acerca do tema, confirmando um avanço inexpressivo no tratamento de esgoto no Estado quando comparado ao panorama nacional, que já não seria expressivo. 
Outro dado importante na avaliação dos serviços de saneamento é a questão das perdas: a nível nacional, $39,2 \%$ da água potável disponível não é contabilizada ou é perdida na distribuição. No Estado do Rio de Janeiro, essa perda cai para 37,8\% (SNIS 2021a; SNIS 2021c).

Quando comparamos os dados de desempenho a nível nacional e no Estado do RJ com os dos operadores privados que atuam há poucos anos em algumas regiões, fica ainda mais evidente a baixa eficiência da estatal. Um dos maiores operadores privados do setor, a empresa AEGEA, aumentou de 27\% em 2006 (início da operação) para 83\% em 2020, a rede coletora de esgoto da capital do Mato Grosso do Sul. Além disso, desde a sua aquisição, reduziu seu índice de perdas na distribuição de água de $55 \%$, para os atuais 19\%, um dos índices mais baixos entre os municípios brasileiros (AEGEA, 2021).

Gráfico 1 - Comparativo entre abrangência de serviços prestados no Brasil e no Estado do Rio de Janeiro

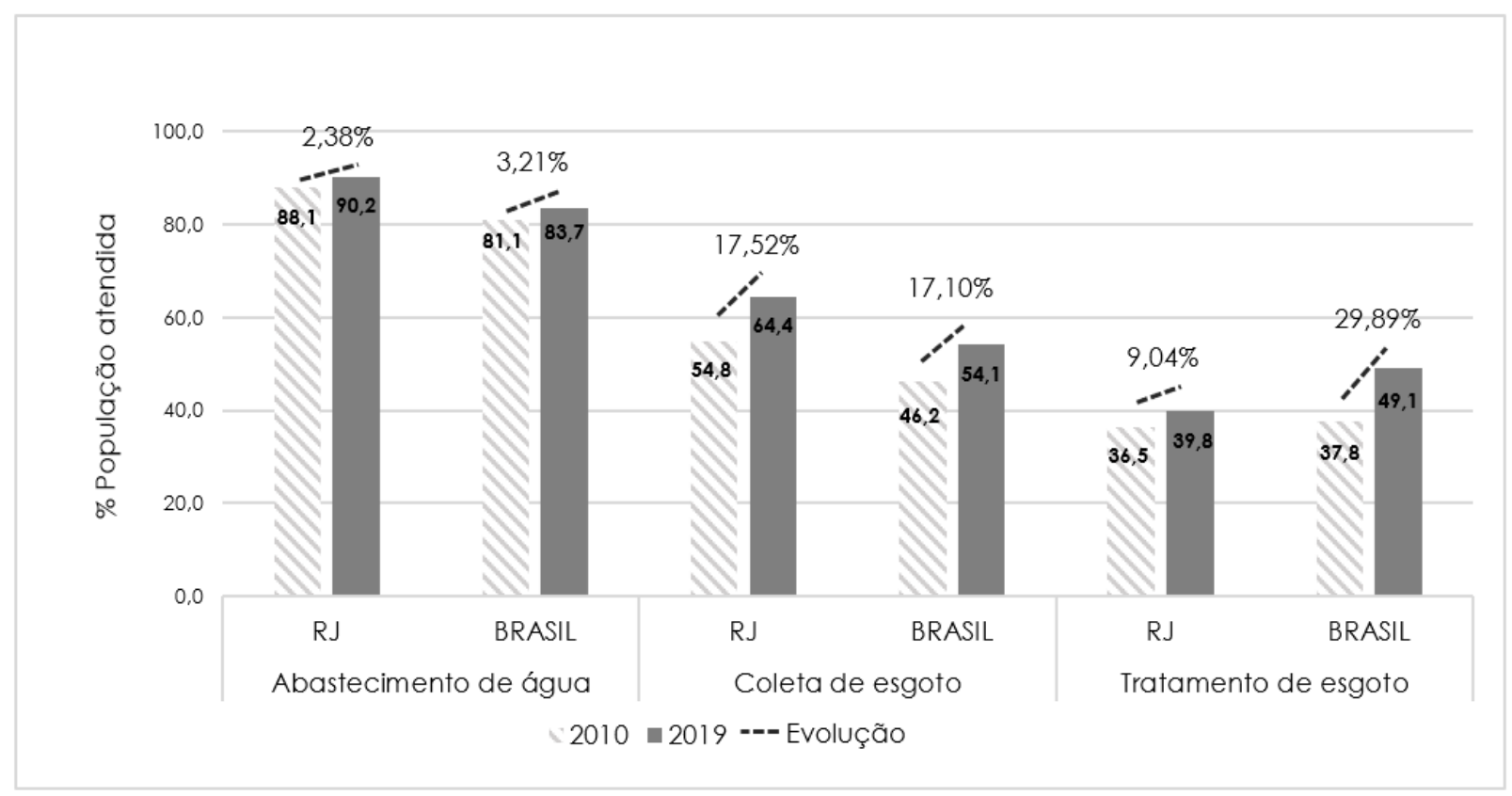

Fonte: Adaptado de SNIS (2021a, 2021b, 2021c)

Já o operador Iguá Saneamento, somente no ano de 2020, construiu mais de 50 quilômetros de novas redes de distribuição de água, onde foram realizadas mais de 10 mil novas ligações. Em redes coletoras de esgoto, foram mais de 63 quilômetros e 6 mil novos pontos de ligação realizados nos cinco estados onde atua (IGUÁ, 2021).

No âmbito do território fluminense, sob a administração do Grupo Águas do Brasil, 3 cidades apresentam os melhores índices de saneamento do Estado: Niterói, Petrópolis e Campos dos Goytacazes. Respectivamente, possuem 95,3\%, 85\% e 94\% de esgoto coletado e tratado, além de $100 \%$ de abastecimento em Campos e Niterói e 96\% em Petrópolis. Destaque para Niterói, que deve atingir a universalização do saneamento básico por meio da nova estação elevatória que teve suas obras iniciadas em 2020 (ÁGUAS DO BRASIL, 2021).

Ainda de acordo com a Companhia, a cidade de Nova Friburgo que, em 2009 (ano que iniciou sua operação) não tinha nenhum litro de esgoto tratado, passou a contar com mais de $92 \%$ ou 8 bilhões de litros por ano e a quase universalização da água tratada (99,82\%). 
O Gráfico 2 reforça e evidencia a diferença na abrangência de atendimento, em números relativos, entre os operadores privados e os públicos. Historicamente, os operadores públicos detêm a maior parte do território nacional e da população atendida, contudo, com as mudanças no Marco Legal e o aumento da participação de empresas particulares neste mercado nos últimos anos, fica ainda mais explícita a maior eficiência e capacidade diferenciada de governança destes novos entrantes.

Gráfico 2 - Comparativo entre abrangência de serviços prestados por operadores públicos e privados no Estado do RJ

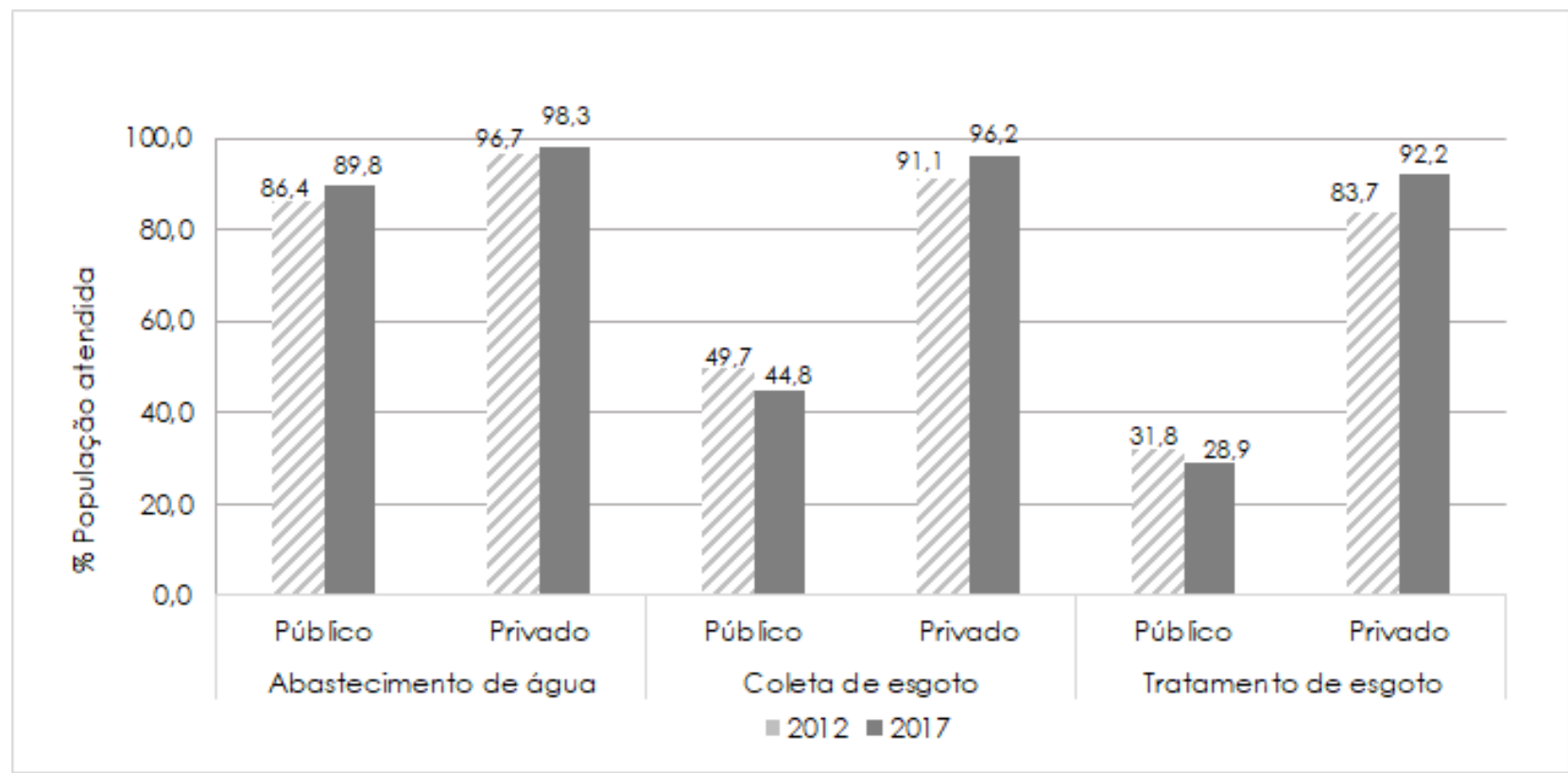

Fonte: Adaptado de ABCON e SINDCON (2019)

\section{HORIZONTES PARA O ESTADO DO RIO DE JANEIRO}

Diante da crítica situação do saneamento em que o Rio de Janeiro se encontra, as empresas vencedoras do leilão encontrarão cenário favorável à melhoria da qualidade na prestação de serviços (TELLES, 2021). Além disso, não é toda a Cedae que está sendo privatizada. Os serviços de captação e tratamento de água limpa que são os mais onerosos continuarão sob a responsabilidade do Estado que a partir de agora não poderá mais contar com os subsídios horizontais internos da Companhia (GIBB, 2021).

Pesquisadores do Insper e da FGV defendem a privatização levando em consideração aspectos como a baixa capacidade de investimento e a governança precária por parte do Estado e o surgimento de interesse por demais investidores, aumentando assim, as chances de atingimento das metas estabelecidas pelo novo marco legal (STEFANO e VASSALO, 2021).

Caso não haja aumento abusivo de tarifas, há uma expectativa de que a aplicação de tais recursos dê celeridade ao propósito da universalização dos serviços de saneamento, atendendo aos 13 milhões de habitantes até 2033, sendo que, de acordo com a Inter.B Consultoria, caso dependesse da governança atual da CEDAE, essa meta somente seria atingida em 140 anos (ELIAS e FLACH, 2021).

Em contrapartida, alguns setores da sociedade questionam o compromisso da iniciativa privada com as classes mais desfavorecidas, bem como a qualidade do serviço prestado. O bloco 3, que representa os 
bairros da Zona Oeste do Rio de Janeiro, não foi arrematado. Acredita-se que o desinteresse por parte das concessionárias tenha sido pelo fato da região ser dominada por grupos paramilitares e que elas não poderiam assumir responsabilidades de futuros conflitos que seriam de responsabilidade e gestão da área de Segurança Pública. Isso mostra como a privatização de serviços básicos à sociedade não devem ser firmados sem o perfeito alinhamento entre as iniciativas públicas e privadas (TELLES, 2021).

\section{CONCLUSÕES}

É notório que o passivo sanitário deixado pela CEDAE é enorme e não fazia parte de sua lista de prioridades. $\mathrm{O}$ esgoto não tratado e a consequente deterioração de patrimônios naturais como a Baía de Guanabara, deixa uma marca indelével na história de uma empresa de tradição centenária e de importância gigante na história sanitária nacional.

Com o leilão e a consequente migração dos serviços de coleta e tratamento de esgoto para a iniciativa privada que, por definição, visa o lucro, é crucial que a concessão ocorra com bases contratuais bem estruturadas e que permitam, em última análise, a participação ativa da sociedade.

Intervenções políticas marcaram a história da CEDAE e foram determinantes para o estabelecimento do cenário atual de governança e nível de serviço. Caso não haja mudança no modelo de gestão do Estado, mesmo com a privatização, é possível que não se alcance os objetivos previstos.

\section{AGRADECIMENTOS}

Aqui registramos nosso agradecimento especial aos familiares e àqueles que de alguma maneira fazem parte dessa caminhada.

\section{REFERÊNCIAS}

ABCON Associação Brasileira das Concessionárias Privadas de Serviços Públicos de Água e Esgoto; SINDCON Sindicato Nacional das Concessionárias Privadas de Serviços Públicos de Água e Esgoto. Panorama da Participação Privada no Saneamento 2019. Disponível em: $<$ http://www.tratabrasil.org.br/uploads/Estudo---PANORAMA-SETOR-PRIVADO-NO-SANEAMENTO2019.pdf> Acesso em: 07 jun. 2021.

AEGEA. Relatório Anual. 2020. Disponível em: <https://ri.aegea.com.br/a-aegea/relatorio-anual/>. Acesso em: 01 jul. 2021

ANTUNES, Paulo de Bessa; D'OLIVEIRA, Rafael Daudt. Breves considerações sobre o novo marco regulatório do saneamento básico - Lei no 14.026, de 15 de julho de 2020. Blog GEN Jurídico. São Paulo, 2020. Disponível em: <http://genjuridico.com.br/2020/07/23/marco-regulatorio-saneamento-basico/>. Acesso em: 01 jul. 2021

BRASIL. Lei nº. 11.445, de 05 de janeiro de 2007. Estabelece diretrizes nacionais para o saneamento básico; altera as Leis nos 6.766, de 19 de dezembro de 1979, 8.036, de 11 de maio de 1990, 8.666, de 21 de junho de 1993, 8.987, de 13 de fevereiro de 1995; revoga a Lei no 6.528, de 11 de maio de 1978; e dá outras providências. Diário Oficial da União. Brasília, DF, 05 jan. 2007. Disponível em: 
<http://www.planalto.gov.br/ccivil_03/_ato2007-2010/2007/lei/L11445compilado.htm>. Acesso em: 03 jul 2021

Lei Federal № 14.026, de 15 de julho de 2020. Atualiza o marco legal do saneamento básico e altera a Lei no 9.984, de 17 de julho de 2000, para atribuir à Agência Nacional de Águas e Saneamento Básico (ANA) competência para editar normas de referência sobre o serviço de saneamento, a Lei $\mathrm{n}^{\circ}$ 10.768, de 19 de novembro de 2003, para alterar o nome e as atribuições do cargo de Especialista em Recursos Hídricos, a Lei no 11.107, de 6 de abril de 2005, para vedar a prestação por contrato de programa dos serviços públicos de que trata o art. 175 da Constituição Federal, a Lei no 11.445, de 5 de janeiro de 2007, para aprimorar as condições estruturais do saneamento básico no País, a Lei no 12.305, de 2 de agosto de 2010, para tratar dos prazos para a disposição final ambientalmente adequada dos rejeitos, a Lei no 13.089, de 12 de janeiro de 2015 (Estatuto da Metrópole), para estender seu âmbito de aplicação às microrregiões, e a Lei oㅜ 13.529, de 4 de dezembro de 2017, para autorizar a União a participar de fundo com a finalidade exclusiva de financiar serviços técnicos especializados. Diário Oficial da União. Brasília, DF, 15 jul. 2020. Disponível em: <http://www.planalto.gov.br/ccivil_03/_ato20192022/2020/lei/L14026.htm>. Acesso em: 27 jun. 2021

CEDAE. A CEDAE: História, 2021. A Criação da CEDAE. Disponível em: <https://cedae.com.br/origem>. Acesso em 30 jun. 2021

A CEDAE: Relatório de administração e demonstrações financeiras 2020, 2021. Disponível em: $<$ https://storage.googleapis.com/site-cedae/balancos/Balanco-financeiro2020.pdf $>$. Acesso em 01 jul. 2021

ELIAS, Juliana; FLACH, Natalia. Leilão da Cedae tem ágio de até 190\% e um bloco sem interessados. CNN Brasil, São Paulo, SP, Reportagem de 30/04/2021. Disponível em: $<$ https://www.cnnbrasil.com.br/business/2021/04/30/servicos-da-cedae-vao-a-leilao-maior-concessao-deinfraestrutura-do-pais-veja> Acesso em 30 jun. 2021

GIBB, Euan. O dinheiro da Previdência canadense está financiando as privatizações do governo Bolsonaro. Revista Carta Capital, São Paulo, SP, Artigo, 06/06/2021. Disponível em: $<$ https://www.cartacapital.com.br/artigo/o-dinheiro-da-previdencia-canadense-esta-financiando-asprivatizacoes-do-governo-bolsonaro/> Acesso em: 30 jun. 2021

GONÇALVES, Mariana Berardinelli Vieira Braz. Privatização Da Cedae: Na Contramão Do Movimento Mundial De Remunicipalização Dos Serviços De Saneamento. Geo UERJ, Rio de Janeiro, RJ, n. 31, p. 81103, dez. 2017. Disponível em: <https://www.epublicacoes.uerj.br/index.php/geouerj/article/view/32057/23047>. Acesso em: 27 jun. 2021

GRUPO ÁGUAS DO BRASIL. Relatório Anual. 2020. Disponível em: <https://www.grupoaguasdobrasil.com.br/wp-content/uploads/2021/05/relatorio-anual-2020-web.pdf . Acesso em: 01 jul. 2021

IGUÁ. Relatórios Anuais. 2020. Disponível em: <https://ri.igua.com.br/informacoes-financeiras/relatoriosanuais/>. Acesso em: 01 jul. 2021

LAHOZ, Rodrigo Augusto Lazzari; DUARTE, Francisco Carlos. A Universalização Do Serviço Público De Saneamento Básico E A Efetividade Do Direito Fundamental À Saúde. Nomos Revista do Programa de 
Pós-Graduação em Direito da UFC, Fortaleza, CE, v. 35, n. 1, jun. 2015. Disponível em: $<$ http://www.periodicos.ufc.br/nomos/article/view/1282/1761>. Acesso em: 27 jun. 2021

MDR MINISTÉRIO DO DESENVOLVIMENTO REGIONAL. Plano Nacional de Saneamento Básico. Brasília, $2019 . \quad$ Disponível em: $<$ https://antigo.mdr.gov.br/images/stories/ArquivosSDRU/ArquivosPDF/Versao_Conselhos_Resolu\%C3\% A7\%C3\%A3o_Alta_-_Capa_Atualizada.pdf>. Acesso em: 27 jun. 2021

NASCIMENTO, Ana Lucia Rodrigues do. Reuso De Água Na Ótica Da Gestão Ambiental. 2010. 34 f. TCC (Graduação) - Curso de Pós-graduação em Gestão Ambiental, Universidade Cândido Mendes, Rio de Janeiro, 2010. Disponível em: <http://www.avm.edu.br/docpdf/monografias_publicadas/k212825.pdf>. Acesso em: 29 jun. 2021

SILVEIRA, Daniel. Leilão da Cedae: entenda o maior e mais importante projeto de infraestrutura recente no país. Globo Notícias. 2021. Disponível em: <https://g1.globo.com/rj/rio-dejaneiro/noticia/2021/04/30/leilao-da-cedae-entenda-o-maior-e-mais-importante-projeto-de-infraestruturarecente-no-pais.ghtml >. Acesso em: 11 set. 2021

SNIS. Sistema Nacional De Informações Sobre Saneamento, 2021. Sistema Nacional de Informação sobre Saneamento - 2019. Disponível em: <http://snis.gov.br/painel-informacoes-saneamento-brasil/web/painelsetor-saneamento>. Acesso em 29 jun. 2021

Sistema Nacional De Informações Sobre Saneamento, 2021. Esgotamento Sanitário - 2019. Disponível em: <http://snis.gov.br/painel-informacoes-saneamento-brasil/web/painel-esgotamentosanitario>. Acesso em 29 jun. 2021

Sistema Nacional De Informações Sobre Saneamento, 2021. Abastecimento de Água - 2019. Disponível em: <http://snis.gov.br/painel-informacoes-saneamento-brasil/web/painel-abastecimentoagua>. Acesso em 29 jun. 2021

STEFANO, Fabiane; VASSALO, Roberta. Privatizem a Cedae: 5 pontos que explicam porque adiar o leilão é péssimo. Revista Exame. São Paulo, 2021. Disponível em: <https://exame.com/economia/privatizem-acedae-5-pontos-que-explicam-porque-adiar-o-leilao-e-pessimo/> Acesso em: 30 jun. 2021

TELLES, Dirceu D'Alkmin. Desdobramentos do leilão da Cedae devem definir os rumos do Saneamento Básico em todo o país. Portal Saneamento Básico, São Paulo, SP, Acervo Técnico, 04/06/2021. Disponível em: <https://saneamentobasico.com.br/acervo-tecnico/leilao-cedae-saneamento-basico/> Acesso em: 30 jun. 2021

TRANSNATIONAL INSTITUTE; PUBLIC SERVICES INTERNATIONAL RESEARCH UNIT; MULTINATIONAL OBSERVATORY. Here to stay: Water remunicipalisation as a global trend. 2014. Disponível em: <https://www.tni.org/files/download/heretostay-en.pdf>. Acesso em: 27 jun. 2021

TRIGUEIRO, André. Governo do RJ ficará com R\$ 14 bi dos R 22 bi do leilão da Cedae; capital terá R 4,3 bi, diz planilha preliminar. Globo Notícias. 2021. Disponível em: <https://g1.globo.com/rj/rio-de- 
janeiro/noticia/2021/05/04/leilao-da-cedae-planilha-preliminar-mostra-valores-preliminares-derepasses.ghtml>. Acesso em: 01 jul. 2021 